\title{
IMPLANTAÇÃO DE ESCOLAS PÚBLICAS ENSINO FUNDAMENTAL EM PRESIDENTE PRUDENTE-SP ENTRE 1964 E 1988
}

Amanda Caleiro da Silva, Yeda Ruiz Maria, Mayara Pissutti Albano, Sibila Corral de Arêa Leão Honda

Universidade do Oeste Paulista - UNOESTE, Faculdade de Engenharias e Arquitetura e Urbanismo, Presidente Prudente, SP.

\section{RESUMO}

As políticas públicas com ação municipal deveriam estar relacionadas à melhora da qualidade de vida da população. E nesse contexto, seria importante que as políticas de educação tivessem relação direta com melhor acesso às escolas e à educação de qualidade. Esta pesquisa teve como foco a análise da implantação de escolas públicas de ensino fundamental I na cidade de Presidente Prudente-SP, relacionando-as ao processo de expansão territorial urbano no período compreendido entre 1964 e 1988. Pode-se verificar que o crescimento da malha urbana não foi acompanhada pela implantação de novas unidades de ensino. No entanto, muitos loteamentos foram aprovados e executados sem relação com o crescimento populacional urbano prudentino, fato que distorce as análises de necessidade de novas unidades no espaço urbano. A metodologia aplicada foi baseada em levantamentos históricos e documentais.

Palavras Chave: Políticas públicas de educação, Ensino fundamental, Expansão territorial urbana, Presidente Prudente.

\section{DEPLOYMENT OF PUBLIC ELEMENTARY SCHOOLS IN PRESIDENTE PRUDENTE-SP BETWEEN 1964 AND 1988}

\begin{abstract}
Public policies with municipal action should be related to the improvement of people's quality of life. In this context, it is important that education policies have a direct relationship with better access to schools and quality education. This research focused on the analysis of the implementation of public elementary schools in the city of Presidente Prudente-SP, relating them to urban territorial expansion process in the period between 1964 and 1988. It can be seen that the growth of the urban area was not accompanied by the implementation of new teaching units. However, many settlements were approved and executed unrelated without regard to the growth of the urban population of Presidente Prudente, whose fact that distorts the analysis of the need for new units in urban areas. The applied methodology was based on historical surveys and documentary.
\end{abstract}

Keywords: Public policies of education, Elemantary education, urban land expansion , Presidente Prudente 


\section{INTRODUÇÃO}

As políticas públicas podem ser identificadas como ações ou não ações dos poderes públicos - federal, estadual ou municipal. Tais políticas devem ser subdivididas em políticas setoriais, entre elas a de educação.

Considerando o aspecto de competências dos poderes públicos sobre determinadas políticas, é importante observar que o município somente foi igualado à União e aos Estados como ente federativo na Constituição Federal de 1988. Anteriormente, os municípios não possuíam competências legais.

Durante o Governo Militar brasileiro (1964-1986), havia total concentração de decisões junto ao governo federal, embora foi nesse período que algumas leis e políticas voltadas ao controle do solo urbano começaram a ser aprovadas, como a Lei n.6.766/1979, em vigor ainda hoje, que dá diretrizes sobre parcelamento do solo urbano.

Com base nesses aspectos, este projeto de pesquisa buscará analisar o processo de implantação de escolas públicas de ensino fundamental I (ou primárias) em Presidente Prudente, Estado de São Paulo, abrangendo período da Ditadura Militar brasileira até a nova Constituição Federal (1988) durante o processo de redemocratização brasileiro.

A metodologia se apoiou em pesquisas teórica e prática, com levantamentos de documentos, de campo (para alocar as unidades de ensino) e mapeamentos.

\section{LEGISLAÇÃO URBANA NO GOVERNO MILITAR BRASILEIRO}

As políticas urbanas estão baseadas nas ações reais e propostas de ação do Poder Público sobre o ambiente urbano, e estão diretamente relacionadas com a gestão e o desenvolvimento urbanos, refletindo no processo de produção do espaço das cidades, segundo incentivos à expansão, à reprodução, ao adensamento, à segregação do espaço urbano, entre outros aspectos (VILLAÇA, 1999; ALVIM, CASTRO, ZIONI, 2010). Assim, as áreas necessárias de atuação do Poder Público local são várias por meio de políticas urbanas específicas, além da identificação das carências no espaço urbano.

A partir da Constituição Federal de 1988, a oferta ou deficiência na oferta de serviços públicos tem como principal responsável o Poder Público local, pois advém de sua política e planejamento urbanos o controle e regulação desses serviços. Anteriormente, era de competência do Poder Público Estadual ou Federal. Considerando o período da Ditadura Militar brasileira, o governo federal centralizava todas as decisões políticas.

No entanto, foi a partir do Governo Militar brasileiro que ocorreram ações para controle do espaço urbano, como a criação do Serviço Federal de Habitação e Urbanismo (SERFHAU), por meio da Lei n.4.380/1964, que direcionava a criação de planos diretores municipais, conhecidos como Plano Diretor de Desenvolvimento Integrado (PDDI) (HONDA, 2011).

Da mesma forma, a Lei n.6.766/1979 foi sancionada visando a estruturar e dar diretrizes mínimas para a expansão territorial urbana, ou seja, definia que os loteamentos deveriam atender a determinados aspectos, como "áreas destinadas a sistema de circulação, a implantação de equipamento urbano e comunitário, bem como a espaços livres de uso público, serão proporcionais à densidade de ocupação prevista para a gleba" (redação original - artigo $4^{\circ}$.), entendendo-se "comunitários os equipamentos públicos de educação, cultura, saúde, lazer e similares".

Dessa forma, os controles ocorriam na esfera municipal por meio de legislação federal. A Constituição Federal (CF) Brasileira (1988), no entanto, alterou significativamente esse processo, pois instituiu os municípios como entes federativos, e entregando-lhes competências comuns e específicas, como dos artigos 182 e 183, sobre política urbana, base para a formulação e aprovação em 2001 da Lei Complementar $n^{\circ} .10 .257 / 2001$.

A partir dessa Constituição, planos diretores tornaram-se obrigatórios para cidades com 
população acima de 20 mil habitantes, focando-se no controle do espaço urbano. O Estatuto da Cidade (Lei Complementar n.10.257/2001) regulamentou os artigos 182 e 183 da CF e definiu instrumentos urbanísticos passíveis de utilização após aprovação nos planos diretores municipais (HONDA, 2011).

A importância do plano diretor como instrumento de política urbana tornou-se bastante expressiva, atribuindo aos municípios a responsabilidade quanto à função social da cidade. E, por meio da política de ordenamento do solo urbano, zoneamento e lei de uso e ocupação do solo urbano, há possibilidade de redução da expansão territorial urbana, diminuindo a pressão para instalação de novos locais de serviços públicos, facilitando a oferta, ou mesmo ampliação da oferta, desses serviços nas estruturas já existentes.

\section{EDIFICAÇÃO ESCOLAR NAS POLÍTICAS PÚBLICAS}

Segundo Pelegrin e Azevedo (2013), no período do Governo Militar, ocorreram ações que submetiam a política e a organização educacional às determinações econômicas mundiais, resultando em um conjunto de medidas de controle e de disciplina sobre a comunidade estudantil. Procurou-se também a formulação de um ordenamento legal, subordinando as estruturas de ensino aos interesses tecnicistas, à racionalização do ensino e ao desprezo às áreas humanas.

Durante a década de 1970 verifica-se a busca por "sistematização e padronização de critérios para uma metodologia de projetos escolares" (AZEVEDO, BASTOS, BLOWER, 2007, p.10). Azevedo (S/D) ratifica essa afirmação, e de acordo com essa autora, o projeto de escola e de toda a rede física também passaram a ser padronizados por meio de Critérios para Elaboração, Aprovação e Avaliação de Projetos de Construções Escolares (CEBRACE), que possuíam regras ("modelo") sobre os aspectos que precisariam ser considerados na elaboração e aprovação dos projetos de escolas.

Em relação à construção de novas escolas, processo de barateamento das construções foi institucionalizado. No Estado de São Paulo, em 1975, devido ao aumento da demanda por vagas, o Governo Estadual buscou racionalizar o sistema projetivo, reduzindo os custos das obras e agilizando suas construções, que culminou na criação da Companhia de Construções Escolares do Estado de São Paulo (CONESP) (AZEVEDO, BASTOS, BLOWER, 2007).

Em 1987, após o processo de redemocratização do país, o Governo Estadual paulista criou a Fundação para o Desenvolvimento da Educação (FDE), que visava a reunir todos os órgãos estaduais que tratavam de assuntos relativos à educação, seja em relação a aspectos físicos quanto pedagógicos (AZEVEDO, BASTOS, BLOWER, 2007).

Nesse mesmo ano, foi formada a Assembleia Nacional Constituinte, cuja Constituição foi sancionada no ano seguinte. Nessa nova carta magna, a competência sobre ensino fundamental voltou a ser dos Estados, mas compartilhada com os Municípios (CF, art.211, §§2‥e 3o.).

\section{PRESIDENTE PRUDENTE-SP E A EXPANSÃO TERRITORIAL URBANA}

Presidente Prudente, cidade média no Estado de São Paulo, foco desta pesquisa, foi aberta a partir de 1917, através do primeiro loteamento urbano - Vila Goulart. A legislação que a aprovou como cidade data de 1921. Desde sua criação, tem no populismo a base de sua política (LEITE, 1972), o que pode ser relacionado com a falta de planejamento urbano. Sua expansão urbana sempre ocorreu de forma mais dinâmica na direção sudoeste.

Até início da década de 1960, a cidade apresentou significativa expansão territorial, sem planejamento e sem regularização legal (SPÓsITO, 1990). Em 1968, o município foi objeto do primeiro plano diretor, denominado Plano Diretor de Desenvolvimento Integrado (PDDI), com metodologia do SERFHAU, elaborado por equipe da Faculdade de Arquitetura e Urbanismo da Universidade de São Paulo (FAU-USP).

Durante a década de 1970, Presidente Prudente apresentou grande expansão territorial 
urbana. A malha urbana praticamente dobrou nesse período. Nos anos seguintes, manteve-se o processo de crescimento da malha urbana, ao mesmo tempo em que era ampliado o processo de segregação espacial com exclusão da população de menor poder aquisitivo para áreas carentes ou sem infraestrutura (HONDA, 2011).

Ou seja, Marisco (2003) afirma que a partir da década de 1970 o processo de urbanização segregacionaista, nesta cidade, agia fortemente no direcionamento da expansão urbana, assim como na destinação das áreas e regiões voltadas às populações de alta e baixa rendas. Segundo Melazzo (1993), durante as décadas de 1970 e 1980, em Presidente Prudente, o processo de expansão territorial foi superior ao ritmo de crescimento populacional e ao número de imóveis urbanos edificados.

Em 1988 foi sancionada a nova Constituição Brasileira. No ano de 1990, foi aprovada a Lei Orgânica do município de Presidente Prudente. E, em 1996, decorrente da obrigatoriedade definida pelas Constituições Federal (1988) e Estadual (1989), foi elaborado e aprovado o novo plano diretor municipal.

Considerando as unidades escolares, verifica-se que em muitos bairros da cidade não receberam unidades escolares, fato que pode ser relacionado com a expansão territorial sem população significativa em cada novo loteamento, como pode ser identificado na Figura 1.

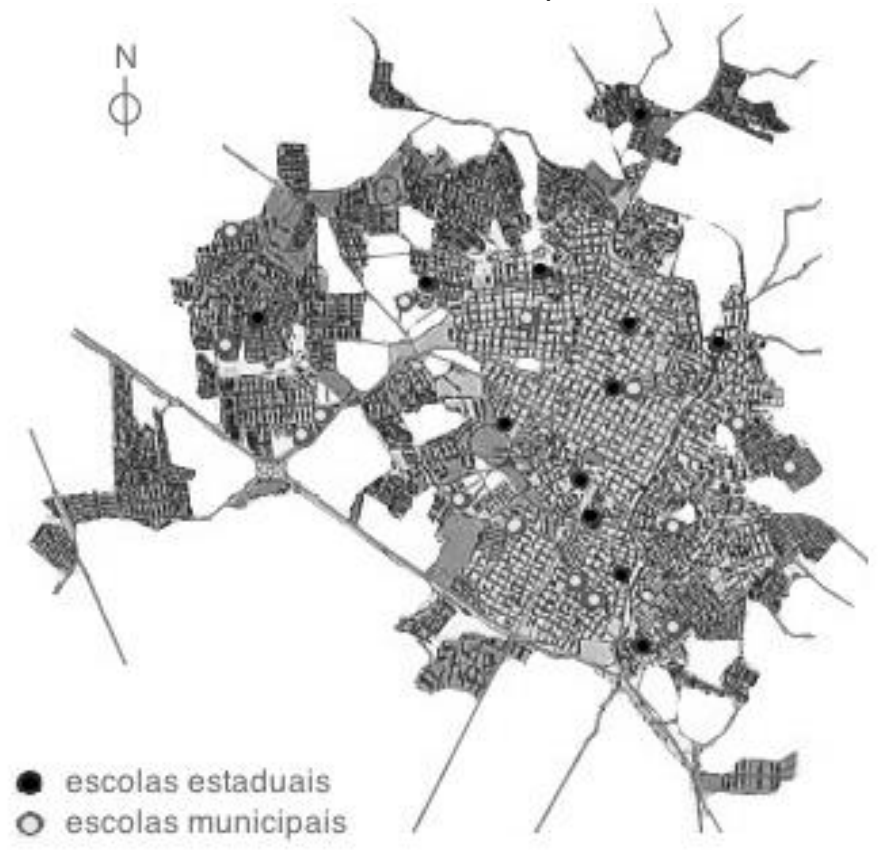

Figura 1. malha urbana de Presidente Prudente em 1988 - localização das escolas públicas de ensino fundamental

(Fonte: autora, 2016)

A partir da Constituição Federal de 1988 e da Constituição Estadual Paulista de 1989, as unidades de ensino fundamental no estado de São Paulo passaram a ser municipalizadas, cujo processo ocorreu em Presidente Prudente a partir dos anos 2000.

\section{CONSIDERAÇÕES FINAIS}

A implantação de novas unidades escolares de ensino fundamental I (antigo primário) não acompanhou o processo de expansão territorial urbano em Presidente Prudente. A falta de diretrizes e/ou controle do crescimento da malha da cidade possibilitou bairros sem população que justificasse os custos de novas escolas.

Dessa forma, observa-se que as políticas de planejamento, de gestão e de educação nessa cidade não têm relação entre si, assim como não têm relação direta com o crescimento da população urbana. 


\section{REFERÊNCIAS}

ALVIM, A.T.B.; CASTRO L.G.R.; ZIONI, S. Avaliação de políticas urbanas. In: ALVIM, A.T.B.; CASTRO, L.G.R. (Org). Avaliação de políticas urbanas: contexto e perspectivas. São Paulo: Romano Guerra, 2010. pp.13-41. https://doi.org/10.7476/9788582930458

AZEVEDO, Giselle A.N. Escolas, Qualidade Ambiental e Educação no Brasil: uma contextualizaçãohistórica. In: Caderno de Boas Práticas na Arquitetura - Eficiência Energética nas Edificações. $\quad$ Vol. $8 . \quad$ IAB-RJ. S/D. Disponível em: http://www.gae.fau.ufri.br/arq pdf/artigos/Giselle\%20Arteiro\%20Nielsen\%20Azevedo/Revista\%20 IAB GiselleArteiro2008.pdf. Acesso em 27.01.2015.

AZEVEDO, G.A.N.; BASTOS, L.E.G.; BLOWER, H.S. O moderno já passado - o passado no moderno. In: Anais do III Seminário Projetar. 2007.

BRASIL. Constituição Federal Brasileira. 1988.

BRASIL. Lei 6.766 de 19 de dezembro de 1979. Dispõe sobre o Parcelamento do Solo Urbano e dá outras Providências.

HONDA, S.C.A.L. Habitação de Baixa Renda como Produto do Capital - o Programa de Arrendamento Residencial (PAR) em Presidente Prudente-SP. 2011. Tese (Doutorado) Universidade Presbiteriana Mackenzie, São Paulo, 2011.

MARISCO, L.M.O. A norma e o fato: abordagem analítica da segregação sócio-espacial e exclusão social a partir dos instrumentos urbanísticos. 2003. Tese (Doutorado) - FCT-UNESP, Presidente Prudente, 2003.

MELAZZO, E.S. Mercado imobiliário, expansão territorial e transformações intra-urbanas: o caso de Presidente Prudente-SP. 1993. Dissertação (Mestrado) - IPPUR/UFRJ, Rio de Janeiro, 1993.

PELEGRIN, T.; AZEVEDO, M.L.N. A educação nos anos de chumbo: a Política Educacional ambicionada pela 'Utopia Autoritária'. In: Revista Pedagogia ao Pé da Letra. 2013. pp.30-44. Disponível em: http://pedagogiaaopedaletra.s3.amazonaws.com/wpcontent/uploads/2013/04/Sele-o-de-textos-sobre-a-Hist-ria-da-Educa-o-no-Brasil-Rep-blica.pdf. Acesso em: 24.fev.2015.

SPÓSITO. E.S. Produção e apropriação da renda fundiária urbana em Presidente Prudente. 1990. Tese (Doutorado) - Faculdade de Filosofia, Letras e Ciências Humanas, Universidade de São Paulo, São Paulo, 1990.

VILLAÇA, F. Uma contribuição para a história do planejamento urbano no Brasil. In: DÉAK, C; SCHIFFER, S.R (Org.). O processo de urbanização no Brasil. São Paulo: EDUSP, 1999, pp.169-243. 